\title{
The Application of Problem-based Learning Approach in English Grammar Instruction: A Pilot Study
}

\author{
Bella Chiou \\ Department of English Language \& Literature, Chinese Culture University, Taipei, Taiwan
}

\begin{abstract}
The study incorporates the problem-based approach (PBL) in the English class with an attempt to improve English low achievers' grammar competence pertaining to relative clauses and their motivation in learning English. Fifty students divided into seven teams with leader for each were recruited. This study adopts the pre- and post-test research design as well as classroom observation checklist and two assignments. The result indicates that the engagement level of the participants is increased by the scenario-based strategy and their grammar competence improves under PBL instruction after being compared with the scores of pretest and posttest, which suggests that the PBL approach really exerts a positive influence on the performance of the participant. The finding also implies that the participants emphasizes, when offering solutions to the scenario, more on employment than on studies, which may reflect their real life experiences.
\end{abstract}

Index Terms-Problem-Based Learning (PBL), English grammar instruction, student-centered approach, collaborative learning, self-directed learning

\section{INTRODUCTION}

Grammar that takes a significant role in English skills provides information beneficial to the learner's comprehension (Zuhriyah, 2017). It is a key in foreign language acquisition, which helps learners construct meaningful words or sentences (Mart, 2013; Tomakin, 2014). In other words, short of grammar knowledge will result in poor performance in foreign language learning.

Students who are classified as being of poor performance in English learning have something in common. As observed in the class, these characteristics include bad learning habits, deficient of preexisting linguistic knowledge, lack of motivation or unwillingness to learn, passive attitude towards learning, low self-esteem or confidence, unwilling to participate in discussion and interactions with peers, ill communicative and expressive abilities, and being unable to solve problems in learning processes leading to be failed in studies. Owing to the above-mentioned factors, these students are labeled as low achievers. How can these phenomena be improved? It is a big challenge for English language instructors.

In a traditional teacher-centered instruction classroom, teachers are responsible for transmitting knowledge to students, as well as monitoring and assessing their learning process and effects. This lectured-based instructional approach, the teacher is an authoritative leader who sets the learning objective for students and designs curriculums and activities for them to accomplish goal set. The extrinsic motivators such as grades and marks are used to motivate students who basically work alone and cooperation is not a choice (Concordia University [CU], 2018; Thomas, 2013). As a result, students often become passive receptors of information and knowledge (Thomas, 2013; Zhang, 2013).

In a student-centered instruction classroom, in contrast, the role of a teacher is a facilitator who helps students take responsibilities for their learning. Instead of listening to the teacher's lectures entirely, students are regarded as the center of the learning process. The teacher serving as a facilitator provides them with opportunities to learn independently. Students interact with their counterparts and group work is encouraged. They also learn to cooperate and communicate with their classmates while working on the tasks that involve interesting methods such as problem-based learning, project-based learning, and scenario-based learning, which increase their intrinsic motivation. Besides, this approach emphasizes evaluating students' learning and learning needs (C U, 2018; Thomas, 2013). Therefore, Collins and O'Brien (2011) conclude that appropriately conducting the student-centered approach can contribute increased motivation to learning, better retention of knowledge, more insightful understanding, and more positive manners towards the subject being taught.

Compared a traditional teacher-centered instruction with a student-centered instruction, the latter appears to have a better chance to deal with the predicaments that low-achievers encounter. Hence, the need for a change is necessary and urgent for low achievers who are suffering from an inappropriate pedagogy.

\section{LITERATURE REVIEW}

\section{A. Necessity of Grammar Teaching}

A good command of grammar is the foundation in the mastery of a language (Wang, 2010). Grammar is important 
because it plays a crucial role in English skills and makes those skills meaningful (Zuhriyah, 2017). English is a foreign language in Taiwan. Students learn the language based on conscious classroom instruction as a subject tested by teachers in school, which cannot be learned subconsciously in a natural setting. After leaving the classroom, students are completely exposed to Chinese language environments. Therefore, grammar instruction is needed in formal education, particularly for English low- achievers who need to properly and purposefully acquire grammar knowledge.

\section{B. PBL Approach}

The PBL, known as a curriculum approach, originated in medical school education in Canada (Barrows, 1996). Later, this approach has been applied in different fields and proved to be effective in teaching and learning (Azman \& Shin, 2012; Peters, 2010; Wong \& Lam, 2007). Its characteristics include student-centered learning, small groups learning, minimal teaching, ill-structured problems proposed at the outset for skill development and used as the vehicle to independently develop problem-solving schemata. During the process analytical and critical thinking is strengthened, and new information acquired through self-directed learning as a lifelong habit (Barrows, 1996). According to Barrows (2002), PBL is a learning approach which uses real-world problems as a starting point for the acquisition and incorporation of new knowledge. It is also a learner-oriented instructional approach with the goal to develop problem-solving skills, takes responsibilities for team work, and eventually, cultivates self-directed learning disposition as a sustainable learning habit (Козлова, 2011; Neville \& Britt, 2008). In other words, in a PBL classroom, obviously, the responsibilities of learners for learning are multiplied. The learning style is active instead of passive. In addition, the role of the instructor simply acts as a facilitator or coach to encourage learners to discover the knowledge for themselves through interacting with different resources (Larsson, 2001; Ng Chin Leoong, 2009; Zuhriyah, 2017).

\section{Rationale for Using PBL in English Class}

The PBL, a constructivist educational approach suitable for all levels of education, is a successful instructional approach for English language learners (Boothe, Vaughn, Hill, \& Hill, 2011; Olssen, 1996). The characteristics of this paradigm and pedagogical strategies are conducive to authentic language learning experiences and information literacy for learners (Boothe et al., 2011). In a PBL classroom, the proposed ill-structured problems are sophisticatedly designed to address the expected learning results. When engaging in discussing the problems, students' prior-knowledge in their native language may equip them to notionally deal with these problems (Boothe et al., 2011), which corresponds with "Conceptual knowledge developed in one language helps to make input in the other language comprehensible" claimed by Cummins (2000, p. 39). Additionally, PBL sustains the Natural approach (Boothe et al., 2011). The Natural approach proposed by Krashen (1988) allows students error-committing without undue stress on error correction to reinforce new language acquisition. PBL sustains this approach because it is different from a traditional classroom where errors cannot be tolerated. Moreover, collaboration and hands-on learning which can decrease the affective filters as well as increase comprehensible input are also important features in PBL. The use of PBL in language classroom not only strengthens language skills but also content knowledge (Boothe et al., 2011). Therefore, PBL is a tentative approach that meets the need of this study attempting to find an alternative instructional model different from the traditional lecture-based approach for English low achievers.

\section{Effects of Previous PBL Research in English Language}

Research studies involved in English learning have manifested that PBL is effective in terms of cultivating students' motivation and enhancing proficiency of English. An action research study conducted in Malaysia to investigate Iraqi students' speaking performance by Keong and Mohammed (2015) indicates that the PBL approach improves the participants' English speaking competence as well as motivates them towards more successful language accomplishments. Moreover, the speaking performance test reveals that the students advance in pronunciation, vocabulary, fluency, and grammar.

Two quasi-experimental research studies are done by Azman and Shine (2012) and Othman, Shah, \& Ismail (2013) in Malaysia. The former examines the attitudes of the university students towards PBL. The finding demonstrates that both motivation and self-confidence of the participant are promoted. The participant self-reported that they were motivated to learn both language and content knowledge through problem-solving. Besides, they are more confident of speaking English for communication and enjoy the collaboration with group members. In general, the participant has a very positive attitude towards PBL claimed by Azman and Shine (2012). The latter applies PBL instruction in an English course to investigate acquisition of course content and language proficiency of the participant. The pre-and-post tests of close test and written test were used to evaluate the outcomes. The finding implies that both PBL group and non-PBL group get improvements in content course in terms of language proficiency and the PBL group displays more improvements than the non-PBL. Besides, the PBL group performs much better than non-PBL in the post-writing test in which support and arguments presented in the essays for each point are richer. (Othman et al., 2013).

In Taiwan, Lin $(2011,2012)$ also attributes her students' progress in English learning and increased motivation to executing PBL in the English classes. Lin used two English video clips and the Internet which combined with the PBL method to explore the effect of her students' text comprehension and their perceptions of PBL. The outcome shows the students make progress in vocabulary knowledge and they agree that their reading skills are enhanced via PBL instruction. Further, Lin (2017) applies PBL in an English reading course to investigate foreign language learners' 
reading comprehension ability, strategy use, and their learning attitudes. The result of the t-test manifests that the participants under PBL instruction whose reading comprehension ability, the ability to identify the subject matter and supportive details, and learning attitude are better than non-PBL students. And their motivation and desire to learn English has been positively affected.

The learning effects of the abovementioned studies prove that PBL model is effective in improving students' capacity for learning English and motivating them towards better language achievements. The current study is inspired by these studies. To improve the learning outcome of low achievers, PBL was adopted to integrate into the English reading course as a vehicle to polish the participant's grammar competence. This approach is a student-centered, small-group, problem-based, collaborative, and self-directed learning approach which provides English low achievers with an opportunity to enable them to rectify their learning habits. The purpose of this study attempts to utilize the PBL model to examine whether or not PBL can boost the low-achievers' grammar competence and motivation to study English. The grammar competence refers to relative pronouns (RPs), RPs as a subject or an object in relative clauses (RCs), and preposition placements in RCs. To fulfill the purpose, the following research questions lead the study:

1. Does the PBL approach improve the student's grammar knowledge about relative clauses in terms of relative pronouns, relative pronouns as a subject and an object, and preposition placements in relative clauses?

2. Does the PBL approach enhance the student's learning motivation in studying English in terms of engagement and involvement in learning process in the English class?

\section{METHOD}

\section{A. Participants}

In total, 50 students who took Freshman English Reading jointed this pilot study, excluding the 3 students who did not take both pre- and post- tests. The participants who had studied English approximately 9-12 years were divided into 7 teams, 6-8 students in one team with a leader. They were at ages 18-21 and all of them spoke Chinese. None of them were English majors. They were mainly from the Colleges of Business, Journalism \& Communication, Engineering, and Arts. Their English proficiency was grouped at the pre-intermediate level based on their scores of the English subject in the General Scholastic Ability Test held by the Joint University Entrance Examination in Taiwan. The total grade levels are 15. The highest level is grade 15; the lowest is grade 1. The grade levels of the participants were between grades 1-4, which was classified as the pre-intermediate level by the Office of Academic Affairs of the University.

\section{B. Instrumentation}

Both qualitative and quantitative research methods are used. This study adopts a pre- and post-test research design, a classroom observation checklist, and 2 classwork as tasks. The tests were administered to assess the participant's knowledge about the RCs before and after practicing the PBL instruction. The two tests that are in multiple-choice format are designed with the same questions but both the questions and the choices of the answers are randomized, 20 questions for each. The maximum score for each test was 100, with each correct response value five points. The classroom observation checklist done by the instructor was used to record what happened during the class. The 2 tasks completed by the participant are used as an indicator to gauge their engagement levels as well as learning achievements. Task 1 requires the participant to offer solutions to the problem the protagonist mentioned in the scenario encounters, task 2 to find out 3RCs from the assigned article and make 3 RCs. Also, the Individual Background Questionnaire is developed to obtain the participant's demographic information, such as their genders, majors, duration for studying English, and English proficiency level, etc.

\section{PBL Treatment and Steps Taken}

This project lasted for 4 weeks with duration of 100 minutes for each week. The general instructional steps taken for implementing PBL instruction are as follows:

First, the participants were grouped into small teams, 6-8 students in one team with a leader.

Second, the instructor proposed the problem to be discussed and distributed the same scenario to each team. The scenario (Appendix A) created by the instructor was related to the article assigned from the textbook. The described situation could happen to the participant in the real world. According to the problem descripted in it, the 7 teams were required to offer solutions to the problem as one of the tasks.

Third, each team participants offered and discussed the possible solutions; meanwhile, the team leader took down the discussion result. The use of Chinese as a medium for communication was allowed to invite them to engage in discussion.

Fourth, each team studied the article and team members helped one another to solve problems they had about the article, such as new words and grammar rules. They were encouraged to utilize different resources to tackle the problems, such as online resources. They were required to identify the RCs in the assigned article and copy them to fulfill part of task 2. In addition, they were demanded to make up $3 \mathrm{RC}$ sentences_which must use a relative pronoun (RP) as a subject, as an object, and a preposition placement that must place in the front of the RP in RCs respectively to complete task 2 . 
Fifth, the instructor acting as a facilitator circulated the classroom to guide the participant to solve their problems. For example, two video clips introducing RCs from Voicetube were given for them to self-discover about RCs as a purpose to review their knowledge about RCs and self-correct misconceptions about RCs if any.

Sixth, each team made an oral presentation to share the solution to the scenario and presented the RCs they found from the article and the 3 RCs made by them.

\section{Data Collection Procedure}

A pretest was administered before implementing PBL instruction as a basis to compare with the posttest. The 7 team participants were given the same scenario and were asked to discuss and offer the possible solutions; meanwhile, the team leader took down the discussion result for the later oral presentation. The result was collected for the later analysis. During the discussion, the instructor went around the classroom to observe and record what happened for later assessment and provided the assistance when necessary. The posttest was conducted one week after the treatment to appraise the participant's knowledge retention and learning achievement.

\section{E. Data Analysis}

Both qualitative and quantitative research methods were used including classroom observations, assigned tasks, and pre- and post-tests. A paired-samples t-test was conducted to compare the difference of pretest and posttest. The discoveries of classroom observations and the 2 tasks were categorized and listed to analyze the participant's intensity of motivation and grammar competence.

\section{RESULT}

\section{A. Analysis of the Effect of Student's Proficiency on Grammar}

Research question 1 examines if the PBL treatment enhances the learning effect of the participant in RCs in terms of RPs, RPs as a subject and an object in RCs, and preposition placements in RCs. The pretest-and-posttest was administered. A paired-samples t-test was conducted to compare the scores of the tests. The result of t-tests demonstrates that there is a significant difference in the scores for the pretest $(\mathrm{M}=37.80, \mathrm{SD}=15.391)$ and the posttest $(\mathrm{M}=49.50, \mathrm{SD}=18.105) ; \mathrm{t}(49)=-4.846, \mathrm{p}=0.000$ as presented on the following Table 1 . The result suggests that the PBL approach have a positive influence on the performance of the participant. Specially, it suggests that after applying the PBL instruction, the participant makes progress in grammar knowledge of the RCs. Apart from the progress making, the result of the posttest also implies that the participants have difficulty in the preposition placement in RCs which gets the lowest correct rate, followed by whose as a RP for the personal possession, unfamiliar vocabulary as the relative pronoun antecedent takes the third place, and only that can be used as the RP followed. Some of them have trouble in subject-verb agreement and verb tenses in RCs and main clauses.

TABLE I

PAIRED SAMPLES TESTS FOR RELATIVE CLAUSES TESTS ( $\mathrm{N}=50)$

\begin{tabular}{l|c|c|c|c|c}
\hline & Mean & SD & $\mathrm{t}$ & df & Sig. (2-tailed) \\
\hline Pretest/Posttest & $37.80 / 49.50$ & $15.39 / 18.11$ & -4.846 & 49 & 0.000 \\
\hline
\end{tabular}

Note. $* p<.05$

In addition, the participants are required to find out three RCs from the article assigned from the textbook and made three sentences in the relative clause (RC) patterns on the team-basis. It is not difficult at all for the 7 teams to pick out 3 RCs from the article. None of them failed to accomplish the task. Since these sentences are copied from the article and examined by the instruction, it seems unnecessary to list them on this paper. As for the three sentences they are required to make they must use a RP as subject and as an object for each; a RP as the object of a preposition for the third sentence. The preposition must be placed in the front of the RP, and the RP cannot be omitted. According to the tasks demonstrated by the 7 teams before the class dismissed, all the sentences are correct based on the above-said rules in spite of a few errors found about preposition placements in RCs, subject-verb agreement, verb tenses, and whose as a RP. These errors are amended immediately after giving hints to them. Compared the result with the posttest, the participants denote their improvements in RCs though the diction in the sentences is daily use vocabulary. Astonishingly, the mistaken usage about the preposition placement in the front of the RP getting the lowest correct rate is self-corrected with minimal teaching. One of the teams from College of Journalism \& Communication find 3 interesting video clips from Youtube which are beneficial to review their knowledge about RCs. Appendix B indicates the RCs made by the participant.

\section{B. Analysis of the Effect of Student's Motivation on Learning English}

Research question 2 investigates whether the participant's learning motivation is enhanced or not. To obtain the data, a classroom observation checklist and a scenario used to get solutions are used to collect the information. The Classroom Observation Checklist for Student Engagement (Appendix C) is developed to keep the records. As observed, the teams composed of the participants from the Colleges of Business, Journalism \& Communication, and Arts whose 
major is Dance are more enthusiastic in discussion. These participants exhibit a very positive attitude. Surprisingly, some of the participants from College of Business tried to speak English to discuss with their members. And the participants whose major was Dance were delightful to share their answers and express innovative ideas without any hesitation. The dynamic atmosphere was full of the classroom. On the other hand, the participants from Arts whose major was Chinese Music appeared to be of no interest and boredom. They would rather do nothing, slide their smart phones, or sit there quietly than participating in discussion with their members. Only when the instructor was approaching them, they pretended to talk with their peers. They displayed a perfunctory and negative attitude. The participants for College of Engineering are moderate. They finished the task on time though they did not attend the discussion vigorously. They sought assistance from outside when they did not know what and how to do.

The solutions for oral presentations used as an indicator to evaluate the participant's engagement are classified into 7 categories and listed on Appendix D. The categories from the $1^{\text {st }}$ category to the $7^{\text {th }}$ contains the solutions to keep a job, to improve learning strategies, to find time for study, to stay awake, to find financial support, solutions unrealistic and erroneous, and the miscellaneous. "Adjust work shifts" under the first category is proposed with the highest frequency among the 7 categories. It seems that the participants are most concerned to stay employed. Eleven solutions are proposed in this category. The second category, solutions to improve learning strategies, talks about how to enhance learning effects. Among them, the suggestion not to take morning classes and withdraw a couple classes is strongly recommended. Other suggestions comprise asking help from teachers and classmates, forming study groups, quitting the job and concentration on study, etc. The third, solutions to find time for study, focuses on time management. Discovering time from a busy schedule to study is advised. The forth, solutions to stay awake, energy drink and alarm clocks are highly recommended. The fifth, solutions to find financial support, comes up with suggestions such as applying for student loans, borrowing money from friends, marrying to a rich woman and working hard to make tuition. The sixth, solutions unrealistic and erroneous, are solutions that cannot come true and are not feasible, like cheating in exams, making a fake diploma, and asking assistance from Doraemon, a character of amination that is omnipotent. The last category, the miscellaneous, offers the opinions such as workout and making decision in either staying in school or employed. More details can be found from Appendix D.

\section{DISCUSSION}

Although the participants make significant progress in grammar knowledge in terms of RCs, the result of the test indicates that the weakness they have in the preposition placement in RCs, the usage of whose as a RP for the personal possession, unknown vocabulary as the relative pronoun antecedent, the case where only that can be used as the RP, and subject-verb agreement in sentences in the posttest. The size of vocabulary is the foundation for mastering English. For these participants whose English proficient level is recognized as pre-intermediate, their vocabulary knowledge, of course, is limited. The unknown vocabulary blocks their judgement to decide which RP should be adopted. There is neither so-called verb conjugation nor the concept of subject-verb agreement in sentences in the Chinese language. They do not get accustomed to the usage unless they are reminded. The participants understand the rules how to use a $\mathrm{RP}$ to replace people and non-people as a subject or an object in RC sentences but they become confused when the sentences that are not presented in the way they are familiar with. For example, the sentence "That storybook which you looked at was very interesting." was easier than "That storybook at which you looked was very interesting." for them to comprehend. Similarly, when encountering whose as a RP, they do not have enough experiences to recognize immediately this "whose" was a RP in RCs. The difficulty they had resulted from their poor knowledge in vocabulary and grammar with respect to RCs. This also reminds English teachers who focus on equipping students with linguistic knowledge such as vocabulary and grammar to prepare them for taking English tests of an efficient teaching method that should be adopted to make learning more effective. Despite the difficulties shown, the participant does improve their grammar competence under PBL instruction overall. The consequence is consistent with Zuhriyah's study (2017), which sustains that there is an improvement on students' grammar ability.

Conspicuously, the engagement level of the participants is increased by the scenario-based strategy. The scenario describes the story which possible takes place around the participant. As witnessed, most of them joined discussion vigorously during which they mediated and compromised their opinions with their team members. They reached a consensus finally. During the process, their social interaction skills certainly are positively influenced (Larsson, 2001). According to the solutions suggested, 11 solutions are proposed to stay hired, which spotlights their concern most. All 7 teams unanimously uphold the notion, Adjust work shifts. The possible reason for this is that most of them have a part-time job with different reasons but they have the same topic to tempt them to discuss the scenario with their team members. The similar story might happen to them or people around them. There is a need for them to talk about, which is the incentive to make them talk. The story might happen in their real lives, which is different from the traditional classroom context considered to be boring and monotonous due to untruthful events or useless skills repeated and taught. The result also reveals that the participant seems to be practical. Staying employed to make money is critical. They put more emphasis on employment than on studies. This maybe reflects their real life experiences.

The tasks which focus on grammar knowledge regarding RCs are employed as a stimulus to learn grammatical skills. Triggered by such a heated discussion on the team-oriented environment, when asked to find out 3 RCs and make 3 $\mathrm{RCs}$, the participant shows a positive manner. They have to know exactly what the RC is. They realize that they have to 
be responsible for their learning to solve the problem. They work collaboratively to fulfill the tasks by self-directed discovery. They start to browse on-line resources where tremendous information is provided. They have to think critically to filter the solutions. After finding the potential solutions, they have to discuss with their members to decide the appropriate solutions for the team to make the oral presentation ready. During the process, they can self-monitor their learning and self-assess their performances and the critical-thinking skill is strengthened as well. In such a circumstance, their knowledge is being instilled subconsciously as well as motivation enhanced by hand-on and collaborative learning. The result echoes the studies of Bauer, Bauer, Revelt, and Kight (2002) and Boothe et al. (2011). They declare collaboration decreases learners' anxiety and increases their level of relaxation and inclusion in the class, which advances their motivation. Under PBL instruction, the participants' learning habits have been changed. They tend to join discussions and interact with their peers more. They are not passive receivers of knowledge anymore; instead they are more independent to explore knowledge with a critical attitude. By doing so, their self-esteem is lifted.

\section{CONCLUSION}

The PBL is an effectual model verified by this study according to the finding. The English low-achievers are successfully motivated by scenario-based strategy which activates their interest and desire to participate in discussion. This student-centered approach empowers them to explore knowledge in their own pace. They feel anxiety-free and comfortable to navigate in the Internet to search the information to best fit their problems, such as RCs. During the process, they are exposed themselves to an English rich environment where they are forced to read in English and make judgements to choose the information they need. Accordingly, not only their knowledge about RSs improves but also the reading skill more or less. The study proves that an active learning manner in learning English is needed. It also contributes to English educators an alternative to guide low-achievers to break through their predicaments and foster their independent learning skills under PBL instruction. This study only lasted for 4 weeks. A longer study duration is recommended to guide students to acquire other grammar knowledge such as verb conjugation, comparative and superlative adjectives, and conditional sentences to examine learning outcomes. A study with a control group and an experimental group is suggested to implement PBL to compare the learning effects of both groups.

\section{APPENDIX A. SCENARIO}

Li Muming is known as a punctual person in the place where he works. Both his colleagues and boss are very nice to him. He always comes to work on time, rain or shine, and hardly ever asks for a leave. Owing to his excellent performance, it does not take long for him to get a salary raise. He is very happy there.

However, Li Muming is late for classes pretty often. He often works the night shifts, which makes him oversleep. As a result, he is late for class. Even when he is in class, he has low energy; he seldom interacts with his classmates; he does not do well at school. His poor school performance makes him feel great pressure and he is definitely not happy at school at all!

Nevertheless, Li Muming does not want to give up his job as well as his studies. How can you help him?

Appendix B. Relative Clauses Made by the 7 Teams

\begin{tabular}{|c|ll|}
\hline Team 1 & (1) & My father is the architect who built our house. \\
& (2) & Jane is the most beautiful woman that I have ever seen. \\
& (3) & The girl at whom you are looking is my sister. \\
\hline Team 2 & (1) & John is my classmate whose mother is a doctor. \\
& (2) & I don't know whom that boy is. \\
& (3) & The tree under which they went camping was the tallest in the park. \\
\hline Team 3 & (1) & I know a lot of my classmates who live close to the school. \\
& (2) & The smart phone which my parent gave me as a gift breaks down. \\
& (3) & Do you know the girl to whom Tom is talking to? \\
\hline Team 4 & (1) & I know a man whose father is your boss. \\
& (2) & The restaurant where we went for is not good. \\
& (3) & This is the pond in which we liked to swim. \\
\hline Team 5 & (1) & The woman who is speaking English is my English teacher. \\
& (2) & The woman whom you talked to just now is my teacher. \\
& (3) & The book for which you are looking is missing. \\
\hline Team 6 & (1) & I don't like people who are unfriendly. \\
& (2) & Do you find the purse which you lost yesterday? \\
& (3) & The issue about which we talked is solved. \\
\hline Team 7 & (1) & The girl who is singing is my friend. \\
& (2) & The friend whom I visited was not home. \\
& (3) & The friend for whom you are looking is away from home. \\
\hline
\end{tabular}

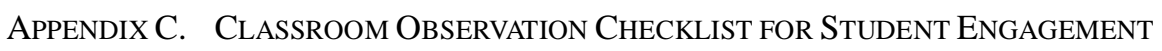

Respond to each statement using the following scale: 1= Meets Expectation; 2= Acceptable but Needs Improvement; 
$3=$ Happened during Class. The behavior meets the statement is ticked.

\begin{tabular}{|c|c|c|c|c|c|c|c|c|c|c|c|c|c|c|c|c|c|c|c|c|}
\hline \multirow{2}{*}{ Statement } & \multicolumn{3}{|c|}{ Team 1} & \multicolumn{3}{|c|}{ Team 2} & \multicolumn{2}{|c|}{ Team 3} & \multicolumn{3}{|c|}{ Team 4} & \multicolumn{3}{|c|}{ Team 5} & \multicolumn{3}{|c|}{ Team 6} & \multicolumn{3}{|c|}{ Team 7} \\
\hline & 1 & 2 & 3 & 1 & 2 & 3 & 1 & 2 & 1 & 2 & 3 & 1 & 2 & 3 & 1 & 2 & 3 & 1 & 2 & 3 \\
\hline The team leader leads the group discussion and keeps notes. & $\mathrm{v}$ & & & $\mathrm{v}$ & & & $\mathrm{v}$ & & $\mathrm{v}$ & & & $\mathrm{v}$ & & & $\mathrm{v}$ & & & & $\mathrm{v}$ & \\
\hline Team members show interest and enthusiasm. & $\mathrm{v}$ & & & $\mathrm{v}$ & & & $\mathrm{v}$ & & $\mathrm{v}$ & & & & $\mathrm{v}$ & & $\mathrm{v}$ & & & & & \\
\hline Team members raise questions. & $\mathrm{v}$ & & & $\mathrm{v}$ & & & $\mathrm{V}$ & & $\mathrm{v}$ & & & & $\mathrm{v}$ & & $\mathrm{v}$ & & & & $\mathrm{v}$ & \\
\hline $\begin{array}{l}\text { 4. Online resources are used to find out answers as well as seek help from the } \\
\text { teacher. }\end{array}$ & $\mathrm{v}$ & & & $\mathrm{v}$ & & & $\mathrm{v}$ & & $\mathrm{v}$ & & & $\mathrm{V}$ & & & $\mathrm{v}$ & & & $\mathrm{v}$ & & \\
\hline Team members are engaged and active. & $\mathrm{v}$ & & & $\mathrm{v}$ & & & $\mathrm{v}$ & & $\mathrm{v}$ & & & & $\mathrm{v}$ & & $\mathrm{v}$ & & & & & \\
\hline $\begin{array}{l}\text { 6. Team members carefully listen to peer questions or opinions and negotiate } \\
\text { the possible answers (critical thinking). }\end{array}$ & $\mathrm{v}$ & & & & $\mathrm{v}$ & & $\mathrm{v}$ & & $\mathrm{v}$ & & & & $\mathrm{v}$ & & $\mathrm{v}$ & & & & & \\
\hline $\begin{array}{l}\text { 7. Team members can stay in the assigned area to discuss on the topic instead } \\
\text { of missing. }\end{array}$ & $\mathrm{v}$ & & & $\mathrm{v}$ & & & $\mathrm{v}$ & & $\mathrm{v}$ & & & $\mathrm{v}$ & & & $\mathrm{v}$ & & & $\mathrm{V}$ & & \\
\hline 8. Collaboration is found during discussion. & $\mathrm{v}$ & & & $\mathrm{v}$ & & & $\mathrm{v}$ & & $\mathrm{v}$ & & & & $\mathrm{v}$ & & $\mathrm{v}$ & & & & $\mathrm{V}$ & \\
\hline 9. The team can finish the task on time. & $\mathrm{v}$ & & & $\mathrm{v}$ & & & $\mathrm{v}$ & & $\mathrm{v}$ & & & & $\mathrm{v}$ & & $\mathrm{v}$ & & & & & \\
\hline 10. English is used or partly used as the medium for discussion. & & $\mathrm{v}$ & & & $\mathrm{V}$ & & & & & & & & & & & & & & & \\
\hline 11. Team members are passive and stay silent or indifferent for most of the time. & & & & & & & & & & & & & $\mathrm{v}$ & & & & & & & $\mathrm{v}$ \\
\hline $\begin{array}{l}\text { 12. Team members display boredom and seem unwilling to participant in } \\
\text { discussion. }\end{array}$ & & & & & & & & & & & & & $\mathrm{v}$ & & & & & & & $\mathrm{v}$ \\
\hline 13. Time is not enough to finish the task. & & & & & & & & & & & & & $\mathrm{v}$ & & & & & & & $\mathrm{V}$ \\
\hline 14. Team members work independently. & & & & & & & & & & & & & & $\mathrm{V}$ & & & & & & $\mathrm{v}$ \\
\hline $\begin{array}{l}\text { P.S. Colleges of Business: T1 and T2; Journalism \& Communication: T3 and T4; En } \\
\text { - T6 that majors in Dancing is more active than T7.; They enjoy sharing the sol } \\
\text { T7 that majors in Chinese Music display boredom and unwilling to participate } \\
\text { T1 leader guides members to discuss and find the solutions. } \\
\text { - T2 members are better in negotiating with their counterparts (Think critically) } \\
\text { - T3 finds } 3 \text { good video clips understood easily, related to RCs from Youtube. } \\
\text { T5 seeks help from other teams in spite of passiveness. }\end{array}$ & & & & & & & & 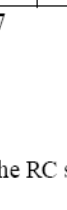 & & & & & & & & & & & & \\
\hline
\end{tabular}

\section{ApPendix D. SOlutions OfFered By the TEAms to the Virtual Role}

\begin{tabular}{|c|c|c|}
\hline A. & Solutions to keep a job & \\
\hline 1. & Adjust work shifts. & $(7)$ \\
\hline 2. & Find another part-time job. & (4) \\
\hline 3. & Transfer to another school nearby his work location. & $(2)$ \\
\hline 4. & Don't work on night shifts. & $(2)$ \\
\hline 5. & Work on weekends instead of weekdays. & $(2)$ \\
\hline 6. & Cut down on the working hours. & $(1)$ \\
\hline 7. & Move to a place where is close to school. & $(1)$ \\
\hline 8. & Drop out of school. & $(1)$ \\
\hline 9. & Find a job during summer and winter vacations instead of school time. & $(1)$ \\
\hline 10. & Find a part-time on campus instead of outside. & $(1)$ \\
\hline 11. & Have someone else to substitute for the virtual role whenever needed. & $(1)$ \\
\hline B. & Solutions to improve learning strategies & \\
\hline 1. & Avoid taking morning classes and withdrawing a couple of classes. & $(6)$ \\
\hline 2. & Ask help from classmates to make up the missed classes or borrow notes from them. & (3) \\
\hline 3. & Build good relationship with classmates and interact with them more. & $(3)$ \\
\hline 4. & Have a good rest to study hard. & $(2)$ \\
\hline 5. & Ask help from teachers. & $(1)$ \\
\hline 6. & Form a study group and discuss schoolwork with peers instead of studying alone. & $(1)$ \\
\hline 7. & Quit the job and focus on study. & $(1)$ \\
\hline 8. & Record teachers' instruction and review it after having a good rest. & $(1)$ \\
\hline C. & Solutions to find time for study & \\
\hline 1. & Manage time wisely for study. & $(3)$ \\
\hline 2. & Find time to study while on duty. & $(1)$ \\
\hline 3. & Make good use of break time to study. & $(1)$ \\
\hline D. & Solutions to stay awake & \\
\hline 1. & Have more energy drink to stay awake during the class. & $(6)$ \\
\hline 2. & Have many alarm clocks around to wake the virtual role up. & (3) \\
\hline E. & Solutions to find financial support & \\
\hline 1. & Apply for a student loan. & $(4)$ \\
\hline 2. & Marry to a rich woman. & $(1)$ \\
\hline 3. & Borrow money from friends. & $(1)$ \\
\hline 4. & Take a couple of years off from school and work hard to make tuition. & $(1)$ \\
\hline F. & Solutions unrealistic or erroneous & \\
\hline 1. & Ask help from Doraemon. & $(1)$ \\
\hline 2. & Make a fake diploma to get a better job. & $(1)$ \\
\hline 3. & Cheat in exams to achieve good grades. & $(1)$ \\
\hline G. & The miscellaneous & \\
\hline 1. & Workout and have interactions with family and friends to reduce the pressure. & $(1)$ \\
\hline 2. & Do not care what others think of you and be brave to be yourself. & $(1)$ \\
\hline 3. & Make a choice: stay in school or keep the job. & $(1)$ \\
\hline
\end{tabular}


*The number in the parentheses indicates the frequency of the statement suggested by the participants on a team-basis.

\section{REFERENCES}

[1] Azman, N., \& Shin, L. K. (2012). Problem-based Learning in English for a Second Language Classroom: Students' Perspectives. International Journal of Learning, 18(6), 109-126. doi: 10.18848/1447-9494/CGP/v18i06/47648.

[2] Barrows, H. S. (1996). Problem-based learning in medicine and beyond: A brief overview. New directions for teaching and learning, 68, 3-12. https://doi.org/10.1002/tl.37219966804.

[3] Barrows, H. S. (2002). An overview of authentic problem-based learning (APBL). In Wee, K. N. L. \& Kek, Y. C. M. Authentic problem-based learning: Rewriting business education (pp. 1-9). Jurong, Singapore: Prentice Hall Asia Pte. Ltd.

[4] Bauer, K., Bauer, G., Revelt, J., \& Kight, K. (2002). A framework for assessing problem-based learning at the University of Delaware. Presented at PBL 2002: A Pathway to Better Learning conference, Baltimore, MD.

[5] Boothe, D., Vaughn, R., Hill, J., \& Hill, H. (2011). Innovative English language acquisition through problem-based learning. In Proceedings of the International Conference: The Future of Education. Available on line: http://conference. pixelonline. net/edu_future/1_morning. php.

[6] Collins, J. W., \& O'Brien, N. P. (2011). The Greenwood dictionary of education. ABC-CLIO.

[7] Concordia University. (2018). Which is best: Teacher-centered or student-centered education? Retrieved on August 3, 2017 from https://education.cu-portland.edu/blog/classroom-resources/which-is-best-teacher-centred-or-student-centred-education/.

[8] Cummins, J. (2000). Language, Power and Pedagogy: Bilingual Children in the Crossfire. Cleveland: Multilingual Matters.

[9] Keong, Y. C., \& Mohammed, A. H. (2015). Improving Iraqi secondary students' speaking performance through problem based learning approach. International Journal of Education and Research, 3(12), 87-96.

[10] Козлова, Н. И. (2011). Problem-Based Learning as an active method of teaching foreign languages. Retrieved on July 26, 2018 from https://moluch.ru/archive/27/2913/.

[11] Krashen, S. (1988). Second Language Acquisition and Second Language Learning. New York: Prentice Hall.

[12] Larsson, J. (2001). Problem-Based Learning: A possible approach to language education. Retrieved on June 26, 2018 from https://www.nada.kth.se/ jla/docs/PBL.pdf

[13] Lin, L. F. (2011). Problem-based learning approach in multimedia foreign language learning. In Global Learn (pp. 1389-1392). Association for the Advancement of Computing in Education (AACE).

[14] Lin, L. F. (2012). The application of the problem-based learning approach to a second language learning context. In EdMedia: World Conference on Educational Media and Technology (pp. 2465-2470). Association for the Advancement of Computing in Education (AACE).

[15] Lin, L. F. (2017). Impacts of the Problem-Based Learning Pedagogy on English Learners' Reading Comprehension, Strategy Use, and Active Learning Attitudes. Journal of Education and Training Studies, 5(6), 109-125.

[16] Mart, C. T. (2013). Teaching grammar in context: why and how? Journal of Theory and Practice in Language Studies, 3(1), 124-129. doi: 10.4304/tpls.3.1.124-129.

[17] Neville, D. O., \& Britt, D. W. (2008). A Problem-Based Learning Approach to Integrating Foreign Language Into Engineering. Foreign Language Annals, 40(2), 226-246. https://doi.org/10.1111/j.1944-9720.2007.tb03199.x.

[18] Ng Chin Leong, P. (2009). The Power of Problem-based Learning (PBL) in the EFL classroom. Retrieved on May 20, 2018 from https://www.apu.ac.jp/rcaps/uploads/fckeditor/publications/polyglossia/Polyglossia_V16_Ng.pdf.

[19] Olssen, M. (1996). Radical constructivism and its failings: Anti-realism and individualism. British Journal of Educational Studies, 44(3), 275-295.

[20] Othman, N., Shah, A., \& Ismail, M. (2013). Problem-based learning in the English language classroom. English Language Teaching, 6(3), 125-134. http://dx.doi.org/10.5539/elt.v6n3p125.

[21] Peters, E. E. (2010). Shifting to a student-centered science classroom: An exploration of teacher and student changes in perceptions and practices. Journal of Science Teacher Education, 21(3), 329-349.

[22] Thomas, M. (2013). Teachers' beliefs about classroom teaching-Teachers' knowledge and teaching approaches. Procedia-Social and Behavioral Sciences, 89, 31-39. https://doi.org/10.1016/j.sbspro.2013.08.805.

[23] Tomakin, E. (2014). Teaching English tenses (grammar) in the Turkish texts: a case of simple Present tense: Iș1l maketi iter. International Journal of Learning \& Development, 4(1), 115-131. https://doi:10.5296/ijld.v4i1.5154.

[24] Wang, F. (2010). The Necessity of Grammar Teaching. English Language Teaching, 3(2), 78-81.

[25] Wong, D. K. P., \& Lam, D. O. B. (2007). Problem-based learning in social work: A study of student learning outcomes. Research on Social Work Practice, 17(1), 55-65.

[26] Zhang, B. (2013). The Integration of Critical Thinking Skills into College Students' Spoken English Classes. Retrieved on May 20, 2018 from https://scholar.google.com.tw/scholar?cluster=14474128838465713586\&hl=zh-TW\&as_sdt=0,5.

[27] Zuhriyah, M. (2017). Problem-Based Learning to Improve Students' Grammar Competence. Register Journal, 10(1), 48-61. doi: 10.18326/rgt.v10i1.875.

Bella Chiou is currently an assistant professor in the Department of English Language and Literature, Chinese Culture University, Taiwan, where she offers courses on English reading and listening. Her research interests include bilingual education, English listening comprehension strategy and beliefs, and L1 use in the English class. 